\title{
Proceeding
}

6th ISPAS International Workshop, 22-23 March 2016. International Society of Performance Analysis of Sport. Carlow, Ireland

\section{Profiling fallers in national eventing competition}

\author{
KAREN D. HENNESSY \\ Institute of Technology Carlow, Carlow, Ireland
}

\begin{abstract}
Numerous fatalities have occurred in the sport of evening over the last number of years. An increased risk of falling has been reported based on fence design (Murray et al., 2004b, Murray et al. 2005, Stachurska et al., 2010), rider knowledge of leading the competition and their perception of pace prior to the fall (Murray et al., 2004b). No research to date has considered the competition profile of the horse, the rider and the horse \& rider partnership. The aim of this research was to explore the competition profile of all cross-country falls in Eventing Ireland (El) competitions in the 2011 to 2014 seasons, by analysing the number of cross country starters, number of fallers, competition level, type-of-fall (rider fall/ horse fall). Competition profile variables analysed included: upgrading horse, upgrading rider, new partnership, new season, cross-country penalties prior to fall, cross country profile of horse. There were 27,176 cross-country starts and 643 falls recorded in the timeframe ( 1 fall per every 42 starters). There was variation in the frequency and type of falls across competition levels, with a higher instance of rider falls in Junior $(2.0 \%)$ and Amateur $(1.8 \%)$ level competition and a higher instance of horse falls in CNC2 (0.9\%) level competition. Of all falls, $40 \%$ involved an upgrading horse, $24 \%$ involved an upgrading rider, $36 \%$ involved a new partnership and $51 \%$ were starting a new competitive season. In an attempt to reduce the risk of cross-country falls and while further research is warranted, these findings would indicate a need for better preparation/training of horses and riders prior to upgrading, when establishing new partnerships and in advance of starting their competitive eventing season. Key words: FENCE DESIGN, CROSS-COUNTRY, HORSE, RIDER, EVENTING IRELAND, FALLING.
\end{abstract}

\section{Cite this article as:}

Hennessy, K.D. (2017). Profiling fallers in national eventing competition. Journal of Human Sport and Exercise, 12(2proc), S480-S491. doi:https://doi.org/10.14198//hse.2017.12.Proc2.01

Corresponding author. Institute of Technology Carlow, Kilkenny Road, Carlow, Ireland

E-mail: Karen.Hennessy@ITCarlow.ie

6th ISPAS International Workshop, 22-23 March 2016. International Society of Performance Analysis of Sport. Carlow, Ireland. JOURNAL OF HUMAN SPORT \& EXERCISE ISSN 1988-5202

(c) Faculty of Education. University of Alicante

doi:10.14198/jhse.2017.12.Proc2.01

S480 | 2017| Proc2 | VOLUME 12

C 2017 University of Alicante 


\section{INTRODUCTION}

The equestrian sport of eventing (Horse Trials) has been part of the summer Olympic Games programme since 1912. It is a three phase competition commencing with the elegant dressage phase where the horse and rider combination are marked on a set of predefined movements within a $40 \mathrm{~m} \times 20 \mathrm{~m}$ or $60 \mathrm{~m} \times 20 \mathrm{~m}$ arena. This requires athleticism, obedience and a high level of training. The second phase is the crosscountry phase where the horse and rider combination jump a track of fixed obstacles, over varying terrain, covering several $\mathrm{km}$, at a set pace per minute (increasing with level of competition) and complete the course within a designated optimum time. This phase requires speed, stamina, courage and athleticism. Show jumping is the third phase, where the horse and rider combination jump a set track of knockable fences within an arena setting. This phase requires athleticism, suppleness and technical ability. Penalties are accumulative across all three phases and the horse/rider combination with the lowest penalty at the end of the competition being the winners. Eventing is an all-round test of horse and rider, but is a high risk sport. The Federation Equestrian International (FEI) do recognise the risks involved, 'Eventing is a complete allround test of horse and rider and a tremendous test of horsemanship, but it is also, and will remain a risk sport' (FEl, 2014a).

\section{High Risk Profile of Eventing}

The high risk profile of eventing has raised concerns. It is considered the most dangerous of all Olympic sports. During the 2012 London Olympic Games, Sonia van Gilder Cooke in the Times July 28, 2012, headlined eventing with 'Equestrian Eventing: The Olympics' Most Dangerous Sport? The slightest miscalculation in the cross country can cost medals, as well as possibly lives'. There were two fatalities in 2013 and nine in the previous 10 years in FEl eventing competition, these nine were with more than 4.6 million cross-country fences jumped ( $\mathrm{FEI}, 2014 \mathrm{~b})$. There were 145,255 starters in the 10 year time frame, giving 1 fatality per 16,139 in starters. Combining International and national competition between 2004 and 2014 there were 29 fatalities related to cross-country falls (FEI). In 2014 on the same day, two international riders lost their lives, one in Germany and one in the UK.

Murray et al. (2005) reported an overall rate in eventing of 0.35 horse falls per 1,000 jumping efforts, this increased to 0.91 per 1,000 jumping efforts for 2 and 3 day eventing (usually international) and decreased to 0.27 horse falls per 1,000 jumping efforts for 1 day events (usually domestic).

The FEl International competition statistics on falls date back to 2004. In the 2004 to 2013 timeframe the FEI noted a decrease in the total falls as a percentage of starters from $6.01 \%$ to $5.26 \%$, horse falls decreasing from $2.02 \%$ to $1.59 \%$, rotational falls decreased from $0.51 \%$ to $0.22 \%$ and non-rotational horse falls decreasing from $1.51 \%$ to $1.37 \%$. There are four levels of Senior International Competition each with their own instances of falls: $1^{*}$ (Novice, 1 fall per every 22 starters), 2* (Intermediate, 1 fall per every 18 starters), $3^{*}$ (Advanced, 1 fall per every 14 starters) and $4^{*}$ (Championship, 1 fall per every 8 starters) (FEl, 2014b).

In National (domestic) competition the average percentage of falls per number of starters was $2.68 \%$ (FEl, 2011) and this lower general trend in National Competitions has been noted since ( $\mathrm{FEl}, 2014 \mathrm{~b})$. O'Brien and Cripps (2008) Australian database SHARE reported 3 faller per 100 starters (3\%), 1.2 falls per 1,000 jumping efforts, 1.8 horse falls per 10,000 jumping efforts and the risk of 0.4 rotational falls per 10,000 jumping efforts.

\section{Risk Comparison to Other Sports (Equestrian and Non)}

Equestrian activity is high risk, but eventing seems to be the highest. Pounder (1984), reported that equestrian riding is considered to have the highest mortality of all sports, with an annual death rate of 1 per 
1 million population and Ingemarson, (1989) reporting a mortality rate of 0.5 per million populations per annum in Sweden. However according to Paix (1999) eventing is the most dangerous of all equestrian sports with an overall injury rate for eventing competitors of one per 14 hours of cross-country riding, making it 70 times as dangerous as horse riding in general. In comparing the risk levels in eventing to other high risk sports, Paix (1999) reported an injury incidence of $0.88 \%$ per competitor per event. This he noted exceeded by more than three times Chapman's (1991) reported incidence of injury rate of $0.24 \%$ for motorcycle racers and $0.14 \%$ for car racers. This view is endorsed by Chitnavis et al. (1996) in noting that horse riding is a dangerous pastime with more accidents occurring per hour than during motor-cycling.

In comparison to horse racing, the risk falls and injury in eventing is lower but the fatality rate in eventing is higher. Turner (2002) conducted a review of studies conducted on horse racing and reported the incidence of falls of $0.37 \%$ for flat racing and $4.8 \%$ for jump racing in Ireland, with injury rates of $0.15 \%$ for flat and $0.6 \%$ for jump racing. Fatalities in the 1992-2000 racing seasons were rare, with one on the flat in GB and one over fences in Ireland. In GB for the 1975-2000 period there were four deaths out of 953,856 rides in flat racing (1 per 238,464 rides) and five deaths out of 773,511 rides(1 per 154,702) in jump racing, giving fatality rates of 419.4 per $100,000,000$ rides in flat racing and 646.4 per $100,000,000$ rides in jump racing respectively. Strickland (2000) in a study of 1,000 riding accident hospital admissions reported 1 injury for 100 hours of leisure riding , 1 injury for 5 hours for amateur racing over jumps and 1 injury for 1 hour of cross-country eventing with the highest injury rates among the riders competing at the highest levels (Paix, 1999). These statistics highlight the increased risk inherent in eventing in comparison to flat or jump racing.

Amongst horse related injuries, falls and in particular rotational falls, incur the highest risk of serious injury or fatal outcome. Hobbs (1994) reported that, where the riders were thrown from the horse and subsequently had the horse fall on them, tend to have more serious injuries. When a horse can weigh up to $500 \mathrm{~kg}$, moves at a speed of $65 \mathrm{~km} / \mathrm{h}$, elevates the rider 3 meters above the ground, Chad et al. (2007), there is very little protection that can be given to the rider if the horse lands on them. This is reflected in FEI stats in that 'the risk of having a serious injury is once every 54 unseated rider falls, to once in every 20 horse falls and finally once in every 5 rotational horse falls, (FEl, 2014 p. 9).

Research into the risk factors associated with falls has to date mainly focused on the type of fence at which the fall was incurred. Previous research has reported increased risks when; taking-off from water, landing into water, a jumping a drop fence (Murray et al., 2004b, Murray et al. 2005), if the fence is angled or has a spread (Murray et al., 2004b), if the fence is a combination fence with successive elements, is a narrow fence, is a brush fences, or is a fences with alternatives (Stachurska et al., 2010). Non-fence related risk factors include; the riders knowledge of leading the competition (Murray et al., 2004b, Murray et al. 2005), the riders perceived approach pace to fence as too fast or too slow (Murray et al., 2004b), if the rider in receipt of cross country coaching (Murray et al., 2004b, Murray et al. 2005) and the earlier performance on the cross country course (Murray et al., 2004b). No research has looked at the risk factors related to the horse/rider competition profiles.

\section{Safety Measures and Injury Preventative Measures}

Annus Horribilis is probably how the British Horse Trials Association (BHTA), now British Eventing, would have described the year of 1999. In that year in the UK alone there were 5 fatalities in eventing. In the wake of such a tragic year, the International Eventing Safety Committee was formed jointly by the BHTA and the FEl. This Committee made the recommendation that 'everything should be done to prevent horses from falling: this single objective should greatly reduce the chance of riders being seriously injured as well as significantly improving the safety of competing horses.' (International Eventing Safety Committee, 2000, p.2). 
There is an acceptance of a level of risk but the onus is being placed on the rider and their judgement of their own and their horses' level of training and competence to compete at a particular level. 'Eventing will remain, a risk sport. The final decision and the ultimate responsibility for participation must continue to remain with the rider. The rider and no-one else has to decide upon the level of training, ability and limits in performance of his/her horse', (FEl, 2014a, p1.) The FEI Eventing Vision Statement states that every effort must be made to ensure that, at each level, responsible athletes are participating with progressively trained horses in order not to be exposed to a higher risk than which is strictly inherent to the nature and level of the competition' (FEl,2014a, p1.).

The FEl have in place an Eventing Risk Managment Action Plan which includes a number of protective measures [rider protection (helmet and back protectors), cross-country fences (frangible and deformable structures)] and preventative measures (including databases, education and minimum eligibility requirements). It is compulsory to wear an approved helmet and back protector. The use of frangible pins and deformable fences would appear to have a substantial role to play in reducing the risk of a horse falling. Research conducted at the Transport Research Laboratory where the analysed the video footage of 100 falls concluded that significant injuries resulted from rotational falls and that if a top rail could give way as much as $20 \mathrm{~cm}$, the horse would have a few fractions of a second to free up its front legs and prevent a rotation, if not the fall, (Walcott, 2003). While this would seem the way forward in reducing the potential of a rotational horse fall, their use in International level competition has been limited. Out of 17,733 fences used in International competition in $2013,514(2.9 \%)$ of them were equipped with frangible/deformable devices (FEl, 2014). Sonia van Gilder Cooke (2012) reporting in advance of the eventing competition at the London Olympics, noted that the FEl still does not mandate frangible/deformable devices use in competition and at the London Olympics only three of the some 40 fences on the cross-country course would be fitted with frangible pins.

Database development is ongoing and National Federations for Eventing reporting on an annual basis to the FEl. They present their fall statistics for the previous year, the trends and proposed changes for the future with a view to improve the safety of the sport including: minimum eligibility requirements (MERs) before competitors move to the next level of competition, downgrading if there are consecutive cross-country falls, improving consistency in standard of cross-country tracks within levels of competition, classification of riders with restrictions.

These databases are sources of research opportunity into providing further insight into falls incurred which can feed into informing decision making on minimum eligibility requirements etc. To date no research has considered looking at competitor profile parameters (competition history) of the horse/ rider combination who incur a fall on the cross-country at national level competition. This can also inform the research happening at international level.

\section{MATERIAL AND METHODS}

Eventing Ireland (EI) is the national governing body for eventing in Ireland. The results for each horse, in each phase of competition, in each venue are captured on within an El database. This includes a breakdown of penalties incurred on the cross-country phase. Therefore a competition case history of any horse and rider competing under El rules has been captured and this including falls incurred on the cross-country phase.

A horse is considered to have fallen when both its shoulder and quarters have touched either the ground or the obstacle and the ground or when it is trapped in a fence in such a way that it is unable to proceed without 
assistance or is liable to injure itself. A rotational fall involved the horses' body rotating over a fixed fence. A rider falls occurs when the rider is separated from their horse in such a way as to necessitate remounting (Eventing Ireland Rule Book 2014).

This study involved a retrospective analysis of the El maintained database of the 2011-2014 competitive seasons. Data reviewed include: the number of cross country starters, number of fallers, the competition level, the type-of-fall (rider/ horse/ unclassified), upgrading horse (fall occurring within 3 outings at new level), upgrading rider (fall occurring within 3 outings at new level), new partnership (fall occurring within 3 outings of new partnership), new season (fall occurring within first 3 outings by horse that season), refusals incurred on the cross-country prior to the fall. This information was recorded on an excel database, reviewed for errors and transferred to SPSS, where basic descriptive statistics were performed.

There were a number of limitations to the study. The data analysis was retrospective and the type of information captured was limited (there was no capture of fence type, ground conditions, approach pace to fence, number of jumping efforts, resulting injuries etc). Therefore limited parameters that could be tested, however those that were tested were novel in comparison to previous research into risk factors for crosscountry falls. The level of detail of the captured data was subject to a reliance on $3^{\text {rd }}$ party capture and input, there are many cases in which a fall was recorded but the type of fall (horse fall or rider fall) was not and hence categorised as unclassified falls. Rotational horse falls were not captured. For the 2011-2014 seasons only the profiles of the cross-country rounds that incurred a fall were extrapolated. The profiles of non-falling starters were not, so comparisons could not be drawn with the larger population. However this analysis is a starting point for future research.

\section{RESULTS AND DISCUSSION}

The eventing competition season in Ireland generally runs from early/mid March to mid/late October. In the four competition seasons from 2011 to 2014 , there were a total of 27,176 starters on the cross-country phase of the competition with 643 falls, $2.4 \%$ of cross-country starters or 1 faller for every 42 starters (Table 1)., across the range of competition levels. This a much lower incidents of falls in comparison to international competition, and is in keeping with trends noted by the FEI (2014b).

Table 1. Overall fall statistics

\begin{tabular}{|c|c|c|c|c|c|}
\hline XC Starters & & XC Falls & No. $(\%)$ & $\begin{array}{c}\% \text { Falls } \\
\text { From Starters }\end{array}$ & $\begin{array}{c}\text { Fall For } \\
\text { Every Starter }\end{array}$ \\
\hline El Total & 27,176 & Total & 643 & $2.4 \%$ & 42 \\
\hline \multirow[t]{3}{*}{$(2011-2014)$} & & Horse Falls & $126(20 \%)$ & $0.46 \%$ & 215 \\
\hline & & Rider Falls & $372(58 \%)$ & $1.37 \%$ & 73 \\
\hline & & Unclassified Falls & $145(22 \%)$ & $0.53 \%$ & 187 \\
\hline
\end{tabular}

Of the 643 cross-country falls, $20 \%$ (126) were horse falls, $58 \%$ (372) were rider falls and 22\% (145) were unclassified falls (Table 1). The fact that over $1 / 5^{\text {th }}$ of falls were not classified is very disappointing and prohibits achieving an overall picture of horse falls or rider falls. This lack of detailed capture of fall type is competition venue related rather than competition level related hence comparison by competition level is still achievable. However moving forward Eventing Ireland must insist on a proper briefing of the fence judges at 
all venues, so as to record the details of all falls incurred on the cross-country phase and to capture the incidence of rotational falls.

\section{Fall Profile Parameters}

Of the total 643 falls incurred in the 2011-2014 seasons, $40 \%$ (258) involved horses that were upgrading to a new competition level, $24 \%$ (155) involved riders that were upgrading to a new competition level, $36 \%$ (228) involved a new horse/rider partnership, 51\% (328) involved a new competition season for the horse, 13\% (82) had incurred at least one refusal earlier in the cross-country round prior to incurring the fall. Table 2 provides the fall profile parameters.

Table 2. Fall Profile Parameters

\begin{tabular}{|c|c|c|c|c|c|c|c|c|c|c|}
\hline & $\begin{array}{c}\text { Upgrading } \\
\text { Horse }\end{array}$ & & $\begin{array}{l}\text { Upgrading } \\
\text { Rider }\end{array}$ & & $\begin{array}{c}\text { New } \\
\text { Partnership }\end{array}$ & & $\begin{array}{c}\text { New } \\
\text { Season }\end{array}$ & & $\begin{array}{c}\text { Previous } \\
\text { stop on } \\
\text { course }\end{array}$ & \\
\hline Total & $\begin{array}{c}\text { Number } \\
258\end{array}$ & $\begin{array}{l}\% \\
40\end{array}$ & $\begin{array}{c}\text { Number } \\
155\end{array}$ & $\begin{array}{l}\% \\
24\end{array}$ & $\begin{array}{c}\text { Number } \\
228\end{array}$ & $\begin{array}{l}\% \\
36\end{array}$ & $\begin{array}{c}\text { Number } \\
328\end{array}$ & $\begin{array}{l}\% \\
51\end{array}$ & $\begin{array}{c}\text { Number } \\
82\end{array}$ & $\begin{array}{l}\% \\
13\end{array}$ \\
\hline
\end{tabular}

There was substantial overlap in the fall profile parameters. Of the upgrading horses $48 \%$ had riders that were upgrading, $61 \%$ involved a new horse/rider partnership, $72 \%$ were starting a new competitive season and $19 \%$ of them had incurred a refusal earlier on the cross-country course. In instances where the rider was upgrading, $69 \%$ were developing a new partnership with the horse, $75 \%$ were starting their new competitive season, $22 \%$ of whom incurred at least one refusal earlier on the cross-country course. In instances where there was a new horse/rider partnership, $89 \%$ were facing into a new competitive season, $17 \%$ incurred at least one refusal earlier on the cross-country course. In instances where the horse was facing into a new competitive season, $14 \%$ incurred at least one refusal earlier on the cross-country course.

When considering the level of overlap between the fall profile parameters, it is very difficult single out one key contributing factor to increasing the risk of a fall, but where there are multiple changes occurring (an upgrading horse, with an upgrading rider, at the start of a new season for the horse or a new partnership, where the rider is upgrading at it is the start of a new competitive season for the horse) these may collectively combine to increase the risk of a fall being incurred.

\section{Levels of Competition}

Each competition venue offers a range of differ levels of competition. These completion levels range from the very top level at national competition (A/CNC3 and CNC3) down to Introductory (EI90) level. There were eight classifications of competition levels considered in this analysis which included national level 3 Star (CNC3: 3,200 - 4,000m, at 570m/min, with 25-35 jumping efforts), 2 Star (CNC2: 2,800 - 3,600m, at $550 \mathrm{~m} / \mathrm{min}$, with 22-32 jumping efforts) and $1 \mathrm{Star}(\mathrm{CNC1}: 1,800-3,000 \mathrm{~m}$, at $520 \mathrm{~m} / \mathrm{min}$, with 18-30 jumping efforts), each of which correspond to the International 3 Star, 2 Star and 1 Star levels respectively. Pre-novice $(1,600-2,800 \mathrm{~m}$, at $475 \mathrm{~m} / \mathrm{min}$, with $18-25$ jumping efforts) and Introductory classes $(1,600-2,800 \mathrm{~m}$, at $450 \mathrm{~m} / \mathrm{min}$, with 18-25 jumping efforts) for less experienced/ young horses, these classes do not have international equivalents. Other categories include Junior (U18) and Pony (U16) and amateur classes for the less experienced amateur riders are included in this study, they have varying levels within categories with associated demands, but International statistics are not produced for these groups. 
Table 3 provides a breakdown of cross-country falls by level of competition and Table 4 provides a breakdown of the profile of falls by level. The subsequent discussion of results will be structured by level of competition, with reference back to the overall statistics.

Table 3. Cross-Country Falls by Competition Level

\begin{tabular}{|c|c|c|c|c|c|c|c|c|c|c|c|c|c|}
\hline & $\begin{array}{c}\text { Tot } \\
\text { al }\end{array}$ & & & & $\begin{array}{c}\text { Hors } \\
e \\
\text { Falls }\end{array}$ & & & $\begin{array}{l}\text { Ride } \\
r \\
\text { Falls }\end{array}$ & & & $\begin{array}{l}\text { Unclass } \\
\text { ified } \\
\text { Falls }\end{array}$ & & \\
\hline Level & $\begin{array}{c}\text { Star } \\
\text { ts }\end{array}$ & $\begin{array}{c}\text { Fal } \\
\text { Is }\end{array}$ & $\begin{array}{l}\% \\
\text { of } \\
\text { Sta } \\
\text { rts }\end{array}$ & $\begin{array}{l}\text { Per } \\
\text { Star } \\
\text { ter }\end{array}$ & $\begin{array}{c}\text { Num } \\
\text { ber }\end{array}$ & $\begin{array}{c}\% \text { of } \\
\text { Start } \\
\text { ers }\end{array}$ & $\begin{array}{c}\text { Per } \\
\text { Star } \\
\text { ter }\end{array}$ & $\begin{array}{c}\text { Num } \\
\text { ber }\end{array}$ & $\begin{array}{c}\% \text { of } \\
\text { Start } \\
\text { ers }\end{array}$ & $\begin{array}{c}\text { Per } \\
\text { Star } \\
\text { ter }\end{array}$ & Number & $\begin{array}{c}\% \text { of } \\
\text { Start } \\
\text { ers }\end{array}$ & $\begin{array}{l}\text { Per } \\
\text { Star } \\
\text { ter }\end{array}$ \\
\hline Total & $\begin{array}{c}271 \\
76\end{array}$ & $\begin{array}{c}64 \\
3\end{array}$ & 2.4 & 42 & 126 & 0.5 & 215 & 372 & 1.4 & 73 & 145 & 0.5 & 187 \\
\hline CNC3 & 167 & 4 & 2.4 & 42 & 1 & 0.6 & 167 & 1 & 0.6 & 167 & 2 & 1.2 & 83.5 \\
\hline CNC2 & $\begin{array}{c}219 \\
0\end{array}$ & 57 & 2.6 & 38 & 19 & 0.9 & 115 & 27 & 1.2 & 81 & 11 & 0.5 & 199 \\
\hline CNC1 & $\begin{array}{c}640 \\
3\end{array}$ & $\begin{array}{c}17 \\
6\end{array}$ & 2.8 & 36 & 43 & 0.7 & 149 & 92 & 1.4 & 70 & 41 & 0.6 & 156 \\
\hline Pre-N & $\begin{array}{c}635 \\
6\end{array}$ & 90 & 1.4 & 71 & 14 & 0.2 & 454 & 50 & 0.8 & 127 & 26 & 0.4 & 244 \\
\hline Intro & $\begin{array}{c}338 \\
7\end{array}$ & 80 & 2.4 & 42 & 6 & 0.2 & 564 & 51 & 1.5 & 66 & 23 & 0.7 & 147 \\
\hline $\begin{array}{c}\text { Junio } \\
r\end{array}$ & $\begin{array}{c}282 \\
0\end{array}$ & 80 & 2.8 & 35 & 11 & 0.4 & 256 & 55 & 2.0 & 51 & 14 & 0.5 & 201 \\
\hline Pony & $\begin{array}{c}309 \\
7\end{array}$ & 75 & 2.4 & 41 & 15 & 0.5 & 206 & 46 & 1.5 & 67 & 14 & 0.5 & 221 \\
\hline $\begin{array}{l}\text { Amat } \\
\text { eur }\end{array}$ & $\begin{array}{c}275 \\
6\end{array}$ & 81 & 2.9 & 34 & 17 & 0.6 & 162 & 50 & 1.8 & 55 & 14 & 0.5 & 197 \\
\hline
\end{tabular}

CNC3 is the highest level of domestic competition, with very few horse/ rider combinations achieving this elite level $(0.6 \%$ of all cross-country starters). It is costly to develop a cross-country course to this standard of competition hence, there were 3 venues with 167 cross-country starters and 4 falls $(2.4 \%$ or 1 per 42 starters), of these fallers: three horses were upgrading, three were starting a new competition season, one was forming a new partnership with an upgrading rider, and two were starting new competitive seasons. Upgrading at the start of a new competitive season, particularly to CNC3 level, may increase the risk of incurring a fall, but the reality of the situation is that there is limited opportunity in Ireland to compete at CNC3, one of which occurs very early on in the competitive season. Proper preparation is required for the start of a new season, particularly when intending to upgrade, however there is also limited opportunity to school (train) for cross-country for CNC3 level. 
Table 4. Fall Profile Parameters by Competition Level

\begin{tabular}{|c|c|c|c|c|c|c|c|c|c|c|c|}
\hline & \multirow[t]{2}{*}{$\begin{array}{l}\text { Total } \\
\text { Falls } \\
\end{array}$} & \multicolumn{2}{|c|}{$\begin{array}{l}\text { Upgrading } \\
\text { Horse }\end{array}$} & \multicolumn{2}{|c|}{$\begin{array}{l}\text { Upgrading } \\
\text { Rider }\end{array}$} & \multicolumn{2}{|c|}{$\begin{array}{l}\text { New } \\
\text { Partnership }\end{array}$} & \multicolumn{2}{|c|}{ New Season } & \multicolumn{2}{|c|}{$\begin{array}{l}\text { Previous stop } \\
\text { on course }\end{array}$} \\
\hline & & Number & $\%$ & Number & $\%$ & Number & $\%$ & Number & $\%$ & Number & $\%$ \\
\hline Level & 642 & 258 & 40 & 155 & 24 & 228 & 36 & 328 & 51 & 82 & 13 \\
\hline 3 (CNC) & 4 & 3 & 75 & 1 & 25 & 1 & 25 & 3 & 75 & 0 & 0 \\
\hline 2 (CNC) & 57 & 18 & 32 & 8 & 14 & 5 & 9 & 18 & 32 & 5 & 9 \\
\hline 1 (CNC) & 176 & 58 & 33 & 24 & 14 & 35 & 20 & 79 & 45 & 19 & 11 \\
\hline Pre-N & 90 & 41 & 46 & 15 & 17 & 45 & 50 & 51 & 57 & 13 & 14 \\
\hline Intro & 80 & 67 & 84 & 40 & 50 & 73 & 91 & 71 & 89 & 20 & 25 \\
\hline Junior & 79 & 25 & 32 & 20 & 25 & 27 & 34 & 36 & 46 & 9 & 11 \\
\hline Pony & 75 & 29 & 39 & 32 & 43 & 24 & 32 & 36 & 48 & 11 & 15 \\
\hline Amateur & 81 & 17 & 21 & 15 & 19 & 18 & 22 & 34 & 42 & 5 & 6 \\
\hline
\end{tabular}

CNC2 level is the $2^{\text {nd }}$ highest level of national competition, with many venues offering CNC2 level competitions. There were 2,190 CNC2 cross-country starters ( $8 \%$ of all cross-country starters) with $2.6 \%$ or 1 per 38 starters incurring a fall. The instance of horse falls was the highest of all competition levels at 1 per 115 starters in comparison to the overall average of 1 per 215 starters. This level of competition places increased demand on the physical capabilities of the horse/rider combination, with increased fence dimensions, increased pace and increased technical difficulty of the cross-country tracks. Of the 57 CNC2 falls, $32 \%$ involved upgrading horses, $14 \%$ upgrading riders, $9 \%$ new partnerships, $32 \%$ were starting a new competition season and $9 \%$ had a stop earlier on the course. These are all below the overall averages respectively. This may indicate that at this level of competition, it is the demands of the cross-country courses (fence dimensions, technicality and pace) that challenge the competitors, increasing the possibility of horse falls. For many horses and riders it is at CNC2 level, the level at which they decide on the potential to progress to more advance levels of competition (CNC3) or realise that they (horse or rider or both) at the top end of their capabilities.

CNC1 is the middle level of national competition and all venues (with the odd exception) offer CNC1 level competitions. There were a total of $6,403 \mathrm{CNC1}$ cross-country starters (24\% of all cross-country starters), with $2.8 \%$ or 1 per 36 of starters incurring a fall, slightly above the overall average of $2.4 \%$, with a slightly higher instance of horse falls. The majority of horses and riders who compete at this level do not progress or aspire to progress to higher levels of competition. Of the 176 falls incurred at CNC1 level, 33\% were upgrading horses, $14 \%$ upgrading rider, $20 \%$ were new partnerships, $45 \%$ were starting a new competitive season and $11 \%$ incurred a refusal earlier on the course, hence all below overall averages. This level of competition provides an opportunity for challenging competition without incurring the increased demands (fence dimensions, technicality and pace) of higher level competition. Some horses and riders are on a progression path, moving up through the levels, heading for higher levels of competition later in their competitive career, however most combinations are within or at the top end of their comfort zone and are happy to remain there at $\mathrm{CNC} 1$ level competition.

Some horses and riders start their competition career at Pre-Novice level others may start at Introductory level. Some horses and riders may stay competing at Pre-Novice level for a long time and some may move to higher levels of competition very quickly. There were a total of 6,356 cross-country starters $(23 \%$ of all cross-country starters) with $1.4 \%$ or 1 per 71 starters incurring a fall. The instance of horse falls was the lowest of all competition levels with 1 horse fall per 454 starters and there was also a lower instance rate of rider falls. These statistics are the among the best of all competition levels and the question is why? Considering 
that of the 90 falls incurred, $46 \%$ of them involved horses that were upgrading to new level of competition (or new to El competition), 50\% of them were forming a new partnerships (in El competition) and $57 \%$ of them were starting a new competitive season (within El). These three falls profile parameters are all higher than the overall average but yet the instances of falls, is considerably lower. Is it to do with the lower height of the fences, the lesser technical demands and/or the slower pace $(475 \mathrm{~m} /$ minute).

Introductory (EI90) level is as implied, is the lowest level of El competition. There were a total of 3,387 crosscountry starters $(12.5 \% \%$ of all cross-country starters) with $2.4 \%$ or 1 per 42 of those starters incurring a fall. The instance of horse falls was the lowest of all competition levels with 1 horse fall per 564 starters but a slightly higher instance rate of rider falls of $1.5 \%$ in comparison to the overall statistics of $1.4 \%$. Again such statistics are good when considering the level of inexperience of most of these horses and many of the riders. Of the 80 falls, $84 \%$ involved an upgrading horse, 50\% involved an upgrading rider, $91 \%$ a new partnership, $89 \%$ a new competitive season. There was a higher instance of refusals incurred prior to the fall $(25 \%)$ than the overall average (13\%) or that of any other competition level. Again the questions to be raised is, are the lower instances of falls to do with the lower height of the fences, the lesser technical demands and/or the slower pace $(475 \mathrm{~m} /$ minute). Further research is required.

In Junior competitions (riders under 18 and generally riding a horse), there were 2,820 starters (10.4\%) of all starters, $2.8 \%$ or 1 in every 35 starters incurred a fall. The instances of rider falls $(2.0 \%)$, was somewhat higher than the overall average (1.4\%). Of the fallers, 32\% involved an upgrading horse, $25 \%$ an upgrading rider, $34 \%$ a new partnership and $46 \%$ a new competitive season, these statistics are all below or on a par with the overall averages. While the percentage forming new partnerships were lower than the overall average, it should be noted that in many instances, the riders may be making the transition from riding ponies to riding horses. Some of these new partnerships were being formed by the riders moving on to more experienced horses. The use of a school master (more experienced horse) to help educate the less experience rider can be very beneficial and educational, but sometimes there can be issues. The experienced horse may have had a long established partnership with another rider, then a new and less experienced rider gets into the saddle, there can be some miscommunication or misunderstanding within the partnership, this may take a little time to resolve. The higher instance of rider falls in this competition level is interesting, and is an area for to be highlighted for further investigation.

Pony classes (riders are U16). There were 3,097 starters (11.4\% of all starters), of which $2.4 \%$ fallers or 1 in every 41 starters incurred a fall. The instances of pony falls $(0.5 \%)$ and the instances of rider falls $(1.5 \%)$, hence are on or close to the overall averages. However $43 \%$ of fall a this level involved an upgrading rider, which was substantially greater than the overall average (24\%). There are certain regulations and guidelines in place to ensure certain levels of competences such as a Letter of Competency signed by an approved instructor or trainer before being allowed to compete (El Rule Book, 2014), the requirement to complete a minimum of 3 cross-country clear jumping rounds in the current or preceding year to move up the Pony grades (EI Rule Book, 2014). Given the high percentage of falls incurred in pony competitions by upgrading riders, it is a recommendation from this research that the requirement of 3 cross-country clears at a previous level prior to upgrading to the next level be reviewed.

Amateur (Sportsman A, B and C and equivalents) classes are open to riders who are over 18, who must not have competed at a high level or internationally in a period of time, in essence their involvement in eventing is as a hobby. There were a total of 2,756 cross-country starters in Amateur competitions $(10.1 \%$ of all crosscountry starters) with $2.9 \%$ or 1 per 34 of those starters incurring a fall. This is the highest instance of falls across all levels of competition. At this competition level the instance of horse falls was $0.6 \%$ or 1 horse fall 
per 162 starters somewhat higher than the overall rate. The instance rate of rider falls of $1.8 \%$, or 1 per 55 starters is high in comparison to the overall statistics. Of the 81 falls incurred in Amateur classes, $21 \%$ involved an upgrading horse, $19 \%$ incurred an upgrading rider, $22 \%$ were forming new partnerships, $42 \%$ were starting a new competitive season, $6 \%$ incurred a refusal earlier on the course prior to the fall. The statistics for all of the other parameters were lower than the overall averages respectively. The amateur classification of the riders is most likely the greatest contributing factor to the higher instances of rider falls within this competition level.

The high instances of upgrading horses (40\%) and upgrading rider $(24 \%)$ could imply a lack of appropriate preparation of the horse or rider in moving up to the next competition level. However a lack of opportunity to school at higher levels has been highlighted through the Riders Forum (2009) where there was a consensus that there was 'a shortage of adequately challenging schooling venues or facilities and what is there prepare horse and rider poorly for advancement to higher levels and stronger tracks. The more extensive use of natural terrain and obstacles would be a very positive step towards the better preparation of combinations for the more advanced classes'. This is something that needs to be considered.

The other aspect of upgrading is the general requirement of 3 cross-country clears at the previous level before progressing to the next level. It is acknowledged that there are varying standards of courses at the levels, with some perceived easier cross-country tracks and some perceived to be more difficult. The Riders Forum (2009) questioned the efficacy of a qualification system (for International Competition) which allows people to carefully select soft options (in terms of the courses they compete on) for qualification to levels where there is no safe place for less than full competence or capability. This could also apply to national level competition. At the Riders Forum (2009) it was also noted that just because you need a qualification does not essentially mean that you are capable and it is an issue of personal responsibility and pragmatism. This reflects back to the FEI stance that 'the final decision and the ultimate responsibility for participation must continue to remain with the rider'. At FEl level there is a rider licensing system, and it was proposed (through the Riders Forum, 2009) to have a horse licensing system. Both such systems could be considered for national level competition along with a rider education programme. Such a programme would identify the risks and aim to improve riders decision making regarding what they ride (horse and level of competition), how they ride and how they react in certain situations and to include fall training. Andrew Nicholson ( 6 times Olympian) suggested that when you cann't see its' (the horses') ears get moving because its ass is coming' (Riders Forum, 2009), essentially it is not going to recover and will result in a horse fall.

Of the falls incurred, $36 \%$ involved new horse and rider partnerships. It may take time to build up a relationship and good communication between the horse and rider. Goodwin et al. (2009) reflected on the limited number of sites on the animal's body for eliciting responses but the vast range of responses required. They note that 'we must always be mindful of the potentially confusing effects of applying pressure signals in common or overlapping site on its body to elicit different responses (Goodwin et al. 2009 p10). New partnerships and/or horses with ever changing riders may experience communication confusion (crossed wires) which may contribute to an increased risk of a fall, again a further area for investigation.

The highest instance of incurring a refusal earlier in the cross-country course was at Introductory level (25\% of fallers). A case could be made where a refusal is incurred, that the rider should retire from competition, however many would argue that it would be very difficult to educate the horse and give a horse experience if they were to retire having incurred a refusal and also that you are teaching the horse that a refusal equates to going home and hence rewarding bad behaviour. Further research is required on this issue. 


\section{CONCLUSIONS}

The falls statistics for national competition in Ireland are lower than those of International competition. But while the general trend is that there are less falls in National competitions than International competition there are many areas in which the safety of participants can be enhanced at national level. A higher instance of horse falls occurred at CNC2 level (more experienced horses) and a lower instance at Pre-novice and Introductory levels (less experienced horses). There was a higher instance rider falls in the Junior and Amateur competition categories. The contributing factors maybe progression to horses for the riders and the riding/competition experience of the Amateurs.

Of the falls incurred, $40 \%$ involved upgrading horses and $25 \%$ involved upgrading riders. There were a high number of falls that had combined parameters (new partnership, upgrading and new season etc.). Where possible riders should try to reduce the number of combined parameters, so if it is a new partnership or a new season then don't upgrade for several runs. Riders should also consider their preparation prior to commencing a new season.

Improvements are required on the recording of fall classifications and rotational falls and while improving the capture of the fall statistics, this alone is insufficient in understanding the risk factors associated with the falls. A comprehensive capture system on the lines of the Australian SHARE database is recommended. A horse and rider licensing system could aid in identifying the at risk participants, supported by a rider education and training programme.

Suggestions for future research include: tracking the competition path of horses and separately of riders through the levels of competition along with their cross-country record at each level; consider the Junior rider transition to horses: consider the instances of falls incurred by horses and their respective riders, where a horse has interchanging riders or numerous riders in a particular timeframe.

\section{REFERENCES}

1. Abu-Zidan, F.M., \& Rao, S. (2003). Factors affecting the severity of horse-related injuries Injury, Int. J. Care Injured., 34, 897-900.

2. Ball, C.G., et al. (2007). Equestrian injuries: incidence, injury patterns, and risk factors for 10 years of major traumatic injuries. The American Journal of Surgery, 193, 636-640.

3. Barber, H.M. (1973). Horseplay: survey of accidents with horses. British Medical Journal, Sept: 8(3), 532-4.

4. Chapman, M.A., \& Oni, J. (1991). Motor racing accidents at Brands Hatch, 1988/9. Br J Sports Med, 25, 121-3.

5. Chitnavis, J.P. et al. (1996). Accidents with horses: what has changed in 20 years? Injury, 27(2), 103-105.

6. FEI (2014a), El Eventing Risk Management Policy and Action plan (updated 14, Feb 2014). http://www.fei.org/system/files/14.02.2014\%20\%20UPDATED\%20FEl\%20Eventing\%20Risk\%20Management\%20Policy.pdf

7. FEl (2014b) Eventing Risk Management Seminar - Lausanne (SUI) Report. http://www.fei.org/fei/disc/eventing/risk-management/seminars-2013

8. Fikri, M. et al. (2003). Factors affecting the severity of horse-related injuries Injury. Int. J. Care Injured, $34,897-900$. 
9. Firth, J.L. (1985). Equestrian injuries. In: Schneider et al. eds. Sports Injuries, Mechanisms, Prevention and Treatment, 23, 431-449.Baltimore: Williams and Wilkins.

10. Goodwin et al. (2009). How equitation science can elucidate and refine horsemanship techniques. The Veterinary Journal, 181, 5-11.

11. Grossman, G.A., et al. (1978). Equestrian injuries: results of a prospective study. JAMA, 240, 18812.

12. Hobbs, G.D., Yealy, D.M., \& Rivas, J. (1994). Equestrian injuries: a 5-year review. J Emerg Med, 12 , 143-5.

13. Ingemarson, H., Grevsten, S., \& Thoren, L. (1989). Lethal horse-riding injuries. J Trauma, 29, 2530.

14. international Eventing Safety Committee. (2000). The International Eventing Safety Committee Report. https://next.fei.org/system/files/2000\%20Safety\%20report.pdf

15. Murray, et al. (2005). Risk factors for cross-country horse falls at one-day events and at two-/threeday events. The Veterinary Journal, 170, 318-324.

16. Murray, et al. (2004a). A retrospective study of horse falls occurring during the cross country phase of horse trials. The Veterinary Record, 154, 207-208.

17. Murray, et al. (2004b). Towards reducing injury to horse and rider in eventing: a case control. In: The Society for Veterinary Epidemiology and Preventive Medicine Proceedings, 50-61.

18. O'Brien, D. \& Cripps, R. Safety for Horses and Riders in Eventing - The SHARE database. Australian Government, Rural Industries Research and Development Corporation. RIRDC Publication No. 08/027.

19. Paix, B.R. (1999). Rider injury rates and emergency medical services at equestrian events. British Journal of Sports Medicine, 33, 46-8.

20. Pounder, D.J. (1984). The grave yawns for the horseman. Equestrian deaths in South Australia 1973-1983. Med J Aust, 141, 632-5.

21. Silver, JR . (2002). Spinal injuries resulting from horse riding accidents. Spinal Cord, 40(6).

22. Stachurska, et al. (2010). Difficulty of cross-country obstacles for horses competing in Three day events. Applied Animal Behaviour Science, 123, 101-107.

23. Strickland, C. (2000). Equine related human injuries. The Horse Interactive October. www.thehorse.com/0010/basics.html.

24. Walcott, K. (2003). Frangible Pins: Making Cross Country Jumps Safer. The Horse. http://www.thehorse.com/articles/13923/frangible-pins-making-cross-country-jumps-safer.

25. Wipper, A. (2000). The Partnership: The Horse-Rider Relationship in Eventing. Symbolic Interaction. doi:10.1525/si.2000.23.1.47 